\title{
GERMINAÇÃO DE SEMENTES PRÉ-EMBEBIDAS E CRESCIMENTO DE PLANTAS DE Artocarpus heterophyllus Lam.
}

\section{GERMINATION OF PRE-SOAKED SEEDS AND INITIAL GROWTH OF Artocarpus heterophyllus Lam. PLANTS}

\author{
Juliana Firmino de LIMA $^{1,3}$ \\ Valdir José de Almeida FONSECA ${ }^{1}$ \\ José Carlos de Cerqueira MORAES ${ }^{1}$ \\ Jorge de ALMEIDA ${ }^{1}$ \\ Elvis Lima VIEIRA ${ }^{2}$ \\ Clovis Pereira PEIXOTO
}

\begin{abstract}
RESUMO
O experimento foi instalado em casa-de-vegetação do Centro de Ciências Agrárias e Ambientais e Biológicas da Universidade Federal do Recôncavo da Bahia, com objetivo de avaliar a germinação de sementes e crescimento de plantas de Artocarpus heterophyllus Lam. (jaqueira), submetidas à pré-embebição. Utilizou-se delineamento inteiramente casualizado com quatro repetições e cinco tratamentos. Os tratamentos foram: sem embebição- T0; nos demais, as sementes foram embebidas por $2 \mathrm{~h}$ em: água destilada - T1; giberelina líquida $\left(\mathrm{GA}_{3} 4 \%\right)$ a $200 \mathrm{~cm}^{3} \mathrm{dm}^{-3}-\mathrm{T} 2$; Stimulate ${ }^{\circledR}$ a $5 \mathrm{~cm}^{3} \mathrm{dm}^{-3}$ - T3 e Stimulate ${ }^{\circledR}$ a $10 \mathrm{~cm}^{3} \mathrm{dm}^{-3}$ - T4. As sementes foram obtidas de frutos maduros de jaca tipo dura, lavadas em água corrente e imediatamente submetidas aos tratamentos. A semeadura foi feita em bandejas de plástico com a parte côncava da semente para baixo e coberta com uma camada de areia. O substrato foi umedecido com água até atingir $60 \%$ de sua saturação hídrica, permanecendo em bancadas, em temperatura ambiente $\left(25 \pm 2{ }^{\circ} \mathrm{C}\right)$. As variáveis avaliadas foram: número de dias para inicio de germinação, número de dias para finalizar a germinação, porcentagem de germinação, índice de velocidade de germinação, comprimento da raiz e do caule, número de folhas e massa seca da raiz, do caule, da folha e total da planta aos 35 dias após a semeadura. Os dados foram submetidos à análise de variância e comparação de médias pelo teste de Tukey a $5 \%$ de probabilidade. A pré-embebição das sementes de jaca dura em água destilada e Stimulate ${ }^{\circledR}$ na concentração de $10 \mathrm{~cm}^{3} \mathrm{dm}^{-3}$ podem ser indicados para a produção mudas com maiores alturas.

Palavras-chave: jaqueira; giberelina; Stimulate ${ }^{\circledR}$; germinabilidade.
\end{abstract}

\section{ABSTRACT}

The Experiment was installed in the greenhouse at the Center of Agricultural, Environmental and Biological Sciences at the Federal University of the Reconcavo Region of Bahia, aiming to evaluate the germination of pre-soaked seeds and initial growth of Artocarpus heterophyllus Lam. plants. The complete random block design was used with fine treatments and four replicates. The treatments were as follows: T1- distilled water, T2- liquid gibberelin at $200 \mathrm{~cm}^{3} \mathrm{dm}^{-3}, \mathrm{~T} 3$ Stimulate ${ }^{\circledR}$ at $5 \mathrm{~cm}^{3} \mathrm{dm}^{-3}$ and T4 - Stimulate ${ }^{\circledR}$ at $10 \mathrm{~cm}^{3} \mathrm{dm}^{-3}$. Sowing was carried out in plastic trays with the concave side of the seeds facing downward and covered with a layer of sand. The substrate was humidified with water until reaching $60 \%$ of the hydric saturation, which were remained in counters under $\left(25 \pm 2{ }^{\circ} \mathrm{C}\right)$ room temperature. The variables evaluated were: number of days until the beginning of seed germination, number of days to finalize germination, germination percentage, root length, stem length, number of leaves, root dry matter, stem dry matter, leaf dry matter, total plant dry matter 35 days after sowing and germination rate. Data was submitted to the analysis of variance, averages compared by the Tukey test at $5 \%$ probability. The pre-soaking of the seeds of hard jack fruit in distilled water, and Stimulate ${ }^{\circledR}$ can be indicated for the production of seedlings with higher height.

Key-words: jack fruit tree; gibberelin; Stimulate ${ }^{\circledR}$; germination capacity.

\footnotetext{
${ }^{1}$ Eng. Agrônomo, doutorando em Ciências Agrárias do Centro de Ciências Agrárias, Ambientais e Biológicas, Universidade Federal do Recôncavo da Bahia, Campus Universitário s/n, Cruz das Almas, Bahia, Brasil. CEP 44380-000. E-mail: juliana_firmino@hotmail.com; valdirfonseca@bol.com.br, jorgealmeida46@bol.com.br, zemoraes42@hotmail.com.

2 Professor Dr. do Centro de Ciências Agrárias, Ambientais e Biológicas, Universidade Federal do Recôncavo da Bahia, Campus Universitário s/n, Cruz das Almas, Bahia, Brasil. CEP 44380-000. E-mail: elvieira@ufrb.edu.br; cppeixot@ufrb.edu.br.

${ }^{3}$ Rua Barreiras, 1084 - Jardim Cruzeiro, Feira de Santana, Bahia, Brasil. CEP: 44015-440. Autor para correspondência
} 
LIMA, J.F. et al. Germinação de sementes pré-embebidas e crescimento...

\section{INTRODUÇÃO}

A jaqueira (Artocarpus heterophyllus Lam.), pertencente à família Moraceae, é uma fruteira exótica introduzida no Brasil ainda nos tempos coloniais na metade do século XVII. É amplamente cultivada em pomares domésticos de todas as regiões tropicais do país, onde ocorrem chuvas intensas durante $\mathrm{o}$ ano agrícola. É originária da Índia, mas hoje esta presente em toda a Ásia tropical (Lorenzi et al., 2006).

Segundo Prado Neto (2007), no Brasil nas condições edafoclimáticas do Recôncavo Baiano, a jaqueira é cultivada, predominantemente em pequenos pomares espontâneos com plantas originárias de semente, que apresenta uma grande variabilidade de genótipos. É explorada na maioria das vezes de forma extrativista, gerando um índice elevado de perda na produção de frutos, principalmente dos genótipos que não apresentam características desejáveis para 0 consumo in natura. Mesmo assim constitui-se em alimento básico para as comunidades rurais.

Devido à falta de informação que possibilite sua exploração econômica e racional, os plantios espontâneos existentes estão sofrendo ação predatória indiscriminada do homem, principalmente para exploração de madeira empregada na construção de móveis de luxo e embarcações.

Para a exploração econômica desta espécie, o conhecimento da qualidade dos frutos por meio de caracteres físicos e químicos, é de fundamental importância para o estímulo do mercado consumidor, como também de sua forma de propagação que proporcione a manutenção das características varietais e agronômicas.

Sendo uma planta alógama de grande porte, que alcança até $25 \mathrm{~m}$ de altura (Donadio et al., 1998), a propagação vegetativa por enxertia é a mais recomendada (Vinha, 1989). As sementes de jaca são recalcitrantes, perdem sua viabilidade em pouco tempo após sua retirada do fruto. Para a formação de porta-enxertos, o conhecimento da germinação das sementes é o primeiro passo para obtenção de mudas vigorosas e de qualidade.

A qualidade fisiológica das sementes tem sido caracterizada pela germinação e pelo vigor, sendo este último definido como a soma de atributos que confere a semente potencial para germinar, emergir e resultar rapidamente em plântulas normais sob ampla diversidade de condições ambientais (Hofs et al., 2004).

$O$ processo germinativo requer a participação ativa da complexa maquinaria de síntese da célula, consistindo assim uma série de enzimas, fatores e co fatores, reguladores hormonais, ácidos nucléicos e caminhos outros ainda não identificados completamente (Vieira, 2001).

Para que uma semente germine, é necessário que o meio forneça água suficiente, permitindo a ativação das reações químicas relacionadas ao metabolismo e, com isto a retomada do processo do desenvolvimento do embrião (Barros, 2006).

Dentre os fatores que regulam o processo germinativo, a presença de hormônios e o equilíbrio entre estes promotores e inibidores de crescimento exercem papel fundamental (Moraes et al., 2002).

$\mathrm{O}$ uso de reguladores vegetais na fase de germinação melhora o desempenho das plântulas, acelerando a velocidade de emergência e realçando o potencial das sementes de várias espécies. O uso de compostos químicos biologicamente ativos, como reguladores e estimulantes vegetais, pode cessar ou diminuir o impacto de fatores adversos na qualidade e desempenho das sementes (Aragão et al., 2003).

Como forma de acelerar e melhorar a germinação de sementes e também promover o crescimento das plantas jovens, vários pesquisadores preconizam o uso de reguladores vegetais. Bewley \& Black (1986) reportaram sobre a presença de hormônios na semente, sendo sua ação relacionada com o crescimento do embrião. Dentre os hormônios presentes nas sementes, o de mais largo espectro de atuação são as giberelinas.

A ação das giberelinas (GAs) ou do ácido giberélico no processo germinativo é bem conhecida. Segundo Metivier (1979), as mesmas atuam no controle da hidrólise do tecido de reserva para o fornecimento de energia ao embrião, promovendo, de acordo com Salisbury \& Ross (1992) o alongamento celular, fazendo com que a radícula se desenvolva através do endosperma ou tegumento.

A mistura de dois ou mais reguladores vegetais ou destes com outras substâncias (aminoácidos, nutrientes, vitaminas) é designada de bioestimulante ou estimulante vegetal. Esse produto químico pode incrementar o crescimento e desenvolvimento vegetal estimulando a divisão celular, diferenciação e o alongamento das células, podendo também, aumentar a absorção e a utilização de água e dos nutrientes pelas plantas (Vieira, 2001).

Com isso, objetivou-se avaliar a germinação de sementes e o crescimento de plantas de Artocarpus heterophyllus Lam, submetidas à pré-embebição com diferentes substâncias reguladoras do crescimento.

\section{MATERIAL E MÉTODOS}

O experimento foi instalado na casa de vegetação de Fisiologia Vegetal do Centro de Ciências Agrárias, Ambientais e Biológicas da Universidade Federal do Recôncavo da Bahia. As sementes de Artocarpus heterophyllus Lam. (Jaca "Tipo Dura") foram obtidas de frutos maduros, lavadas em água corrente e imediatamente submetidas aos tratamentos.

Utilizou-se delineamento inteiramente casualizado com quatro repetições de 25 sementes e cinco tratamentos: T0 - sem embebição; nos demais, as sementes foram embebidas por $2 \mathrm{~h}$ em água destilada (T1); giberelina líquida $\left(\mathrm{GA}_{3} 4 \% \mathrm{~L}\right)$ a 
LIMA, J.F. et al. Germinação de sementes pré-embebidas e crescimento...

$200 \mathrm{~cm}^{3} \mathrm{dm}^{-3}$ (T2); Stimulate ${ }^{\circledR}$ a $5 \mathrm{~cm}^{3} \mathrm{dm}^{-3}$ (T3) e Stimulate ${ }^{\circledR}$ a $10 \mathrm{~cm}^{3} \mathrm{dm}^{-3}$ (T4). O GA $4 \%$ é um regulador vegetal líquido à base de ácido giberélico. O Stimulate ${ }^{\circledR}$ é um biorregulador vegetal composto por três reguladores vegetais $(0,009 \%$ de cinetina, $0,005 \%$ de ácido giberélico, $0,005 \%$ de ácido indolbutírico e $99,98 \%$ de ingredientes inertes de acordo com STOLLER DO BRASIL (1998).

Após aplicação dos tratamentos, as sementes foram levadas para casa de vegetação e colocadas para germinar em bandejas de plástico perfuradas $(442 \mathrm{~cm} \times 280 \mathrm{~cm} \times 75 \mathrm{~cm})$, contendo areia lavada e peneirada. Cada caixa recebeu 25 sementes para cada repetição por tratamento. $\mathrm{Na}$ semeadura as sementes foram colocadas com a parte côncava para baixo e cobertas com uma camada de areia e o substrato foi umedecido com água destilada até atingir $60 \%$ de sua saturação hídrica, onde permaneceram em bancadas, em temperatura ambiente $\left(25 \pm 2{ }^{\circ} \mathrm{C}\right)$. A irrigação aconteceu diariamente.

As variáveis avaliadas foram: número de dias para inicio de germinação (NIG), anotando o tempo para a primeira semente germinar; número de dias para finalizar a germinação (NEG), utilizouse de registros diários após o início da germinação anotando-se o tempo para a completa germinação; porcentagem de germinação (\%GE), índice de velocidade de germinação (IVG), comprimento da raiz (CR) e do caule (CC), número de folhas (NF), massa seca de raiz (MSR), do caule (MSC), de folhas (MSF) e total da planta (MST) aos 35 dias após a semeadura. O IVG foi obtido conforme fórmula de Borghetti e Ferreira (2004). A determinação da massa seca de raiz, caule e folha seguiram a metodologia utilizada por Lima et al. (2007). Os dados foram submetidos à análise de variância e comparação de médias pelo teste de Tukey a $5 \%$ de probabilidade. Não houve necessidade de transformação dos dados para atendimento das pressuposições da análise da variância.

\section{RESULTADOS E DISCUSSÃO}

Para as variáveis, número de dias para inicio de germinação (NIG), número de dias para finalizar a germinação (NEG), porcentagem de germinação (\%GE) e índice de velocidade de germinação (IVG), a análise de variância não demonstra diferenças significativas entre os tratamentos (Tabela 1). Em jenipapo, Prado Neto et al. (2007) encontraram o IVE com média 2,29, sendo superior aos encontrados nesta pesquisa. Isto se deve ao comportamento diferenciado entre estas espécies.

TABELA 1 - Número de dias para inicio de germinação (NIG), número de dias para finalizar a germinação (NEG), porcentagem de germinação (\%GE) e índice de velocidade de germinação (IVG) das sementes de jaqueira tipo dura submetidas a diferentes tratamentos de embebição. Cruz das Almas - BA, 2007.

\begin{tabular}{lllll}
\hline Tratamentos & NIG (dias) & NEG (dias) & \%GE & IVG \\
\hline T0 - sem embebição & $17,75 \mathrm{a}^{1}$ & $15,50 \mathrm{a}$ & $76,00 \mathrm{a}$ & $0,83 \mathrm{a}$ \\
T1 - água destilada & $16,50 \mathrm{a}$ & $12,50 \mathrm{a}$ & $80,00 \mathrm{a}$ & $1,04 \mathrm{a}$ \\
T2 - giberelina líquida $200 \mathrm{~cm}^{3} \mathrm{dm}^{-3}$ & $17,25 \mathrm{a}$ & $16,75 \mathrm{a}$ & $79,00 \mathrm{a}$ & $0,86 \mathrm{a}$ \\
T3 - Stimulate ${ }^{\circledR}$ a $5 \mathrm{~cm}^{3} \mathrm{dm}^{-3}$ & $16,25 \mathrm{a}$ & $14,75 \mathrm{a}$ & $79,00 \mathrm{a}$ & $0,88 \mathrm{a}$ \\
T4 - Stimulate ${ }^{\circledR}$ a $10 \mathrm{~cm}^{3} \mathrm{dm}^{-3}$ & $17,25 \mathrm{a}$ & $15,25 \mathrm{a}$ & $84,00 \mathrm{a}$ & $0,93 \mathrm{a}$ \\
\hline C. V $\%$ (1) & 9,16 & 16,77 & 10,82 & 14,81 \\
\hline "Médias seguidas da mesma letra na vertical não diferem entre si ao nível de $5 \%$ de probabilidade, pelo teste de Tukey. CV \\
= Coeficiente de variação.
\end{tabular}

De acordo Souza et al. (2002) a aplicação de ácido giberélico em sementes de porta enxertos cítricos também não surtiu efeito significativo sobre a germinação. Tal fato foi atribuído a um adequado nível endógeno de giberelina nas sementes, de forma que a adição de ácido giberélico não interferiu em seu desempenho durante a germinação.

Stenzel et al. (2003), conduziram trabalho visando à superação da dormência em sementes de atemóia e fruta-do-conde, e concluíram que o uso do ácido giberélico com 50 ou $100 \mathrm{~cm}^{3} \mathrm{dm}^{-3}$ de $\mathrm{GA}_{3}$ proporcionaram taxa de germinação e velocidade de germinação significativamente superiores aos demais tratamentos, independentemente do material genético. Desta forma, a resposta aos tratamentos pelas sementes depende de vários fatores, principalmente do potencial de germinação entre espécies, como também a interação entre os fatores que podem afetar a viabilidade da semente.

Manica (2002) recomenda para acelerar a germinação de sementes de jaqueira, deixá-las em água pelo período de $24 \mathrm{~h}$ antes da semeadura. Segundo este autor as sementes de jaca possuem um percentual muito elevado de germinação, mas que se mantém por pouco tempo, sendo, portanto, recomendado a semeadura tão logo sejam retiradas dos frutos. Esta afirmação está de acordo com o resultado obtido nesta pesquisa, em que as sementes de jaca dura alcançaram um percentual médio de germinação de $79,60 \%$.

A análise de variância para comprimento de raiz (CR) e número de folhas (NF) das plântulas de jaqueira tipo dura, aos 35 dias após a semeadura nos diversos tratamentos, não mostrou efeito significativo (Tabela 2). 
LIMA, J.F. et al. Germinação de sementes pré-embebidas e crescimento...

TABELA 2 - Comprimento da raiz (CR), do caule (CC) e número de folhas (NF) das plantas de jaqueira tipo dura aos 35 dias após a semeadura em diferentes tratamentos de embebição. Cruz das Almas - BA, 2007.

\begin{tabular}{lccc}
\hline Tratamentos & CR $(\mathrm{cm})$ & CC $(\mathrm{cm})$ & NF \\
\hline T0 - sem embebição & $8,91 \mathrm{a}$ & $13,09 \mathrm{~b}$ & $2,31 \mathrm{a}$ \\
T1 - água destilada & $8,81 \mathrm{a}$ & $17,14 \mathrm{a}$ & $2,69 \mathrm{a}$ \\
T2 - giberelina líquida $200 \mathrm{~cm}^{3} \mathrm{dm}^{-3}$ & $8,62 \mathrm{a}$ & $15,80 \mathrm{a} \mathrm{b}$ & $2,13 \mathrm{a}$ \\
T3 - Stimulate ${ }^{\circledR}$ a $5 \mathrm{~cm}^{3} \mathrm{dm}^{-3}$ & $10,28 \mathrm{a}$ & $15,72 \mathrm{a} \mathrm{b}$ & $2,19 \mathrm{a}$ \\
T4 - Stimulate ${ }^{\circledR}$ a $10 \mathrm{~cm}^{3} \mathrm{dm}^{-3}$ & $11,06 \mathrm{a}$ & $16,77 \mathrm{a}$ & $2,50 \mathrm{a}$ \\
\hline C. V $\%$ (\%) & 16,14 & 10,39 & 12,60 \\
\hline Médias seguidas da mesma letra na vertical não diferem entre si ao nível de 5\% de probabilidade, pelo teste de Tukey. CV \\
= Coeficiente de variação.
\end{tabular}

Observa-se que para o comprimento de caule (CC), o tratamento T1 (água destilada) e o T4 (Stimulate ${ }^{\circledR}$ a $10 \mathrm{~cm}^{3} \mathrm{dm}^{-3}$ ) apresentaram valor médio superior ao tratamento T0 (sem embebição). Os resultados encontrados mostraram que nem todos os tratamentos com embebição, apresentaram resposta positiva para a variável comprimento do caule. Resultados semelhantes foram obtidos por Prado Neto et al. (2007) estudando a germinação de sementes de jenipapeiro submetidas à pré-embebição em regulador e estimulante vegetal. Maiores comprimentos de raízes e de plântulas de jenipapo foram obtidos com o uso de Stimulate ${ }^{\circledR}$ a $10 \mathrm{~cm}^{3}$ $\mathrm{dm}^{-3}$ em pré-embebição das sementes por $12 \mathrm{~h}$.
$\mathrm{Na}$ Tabela 3 estão apresentadas às médias para a massa seca da raiz (MSR), massa seca do caule (MSC), massa seca de folhas (MSF) e massa seca total (MST) das plantas de jaqueira tipo dura, aos 35 dias após a semeadura. Pode-se observar que, para a massa seca da raiz (MSR) e do caule (MSC), não foram observadas diferenças entre os tratamentos. Para a massa seca de folhas (MSF), os resultados mostram diferenças entre os tratamentos, sendo o tratamento sem embebição $\left(0,123 \mathrm{~g} \mathrm{planta}^{-1}\right)$, superior aos tratamentos T1 e T2, com valores médios de 0,065 e 0,068 g planta $^{-1}$, respectivamente. Na Tabela 3 , também pode-se verificar que a massa seca total (MST) apresentou comportamento semelhante em todos os tratamentos.

TABELA 3 - Massa seca de raizes (MSR), massa seca do caule (MSC), massa seca de folhas (MSF) e massa seca total (MST) das plantas de jaqueira tipo dura, aos 35 dias após a semeadura submetidas a diferentes tratamentos de embebição. Cruz das Almas - BA, 2007.

\begin{tabular}{lllll}
\hline \multicolumn{1}{c}{ Tratamentos } & $\begin{array}{l}\text { MSR } \\
\left(\mathrm{g} \mathrm{planta}^{-1}\right)\end{array}$ & $\begin{array}{l}\text { MSC } \\
\left(\mathrm{g} \mathrm{planta}^{-1}\right)\end{array}$ & $\begin{array}{l}\text { MSF } \\
\left(\mathrm{g} \mathrm{planta}^{-1}\right)\end{array}$ & $\begin{array}{l}\text { MST } \\
\left(\mathrm{g} \mathrm{planta}^{-1}\right)\end{array}$ \\
\hline T0 - sem embebição & $0,150 \mathrm{a}^{1}$ & $0,113 \mathrm{a}$ & $0,123 \mathrm{a}$ & $0,403 \mathrm{a}$ \\
T1 - água destilada & $0,105 \mathrm{a}$ & $0,115 \mathrm{a}$ & $0,065 \mathrm{~b}$ & $0,285 \mathrm{a}$ \\
T2 - giberelina líquida cm $\mathrm{dm}^{-3}$ & $0,082 \mathrm{a}$ & $0,103 \mathrm{a}$ & $0,068 \mathrm{~b}$ & $0,248 \mathrm{a}$ \\
T3 - Stimulate ${ }^{\circledR}$ a $5 \mathrm{~cm}^{3} \mathrm{dm}^{-3}$ & $0,085 \mathrm{a}$ & $0,118 \mathrm{a}$ & $0,095 \mathrm{ab}$ & $0,295 \mathrm{a}$ \\
T4 - Stimulate ${ }^{\circledR}$ a $10 \mathrm{~cm}^{3} \mathrm{dm}^{-3}$ & $0,082 \mathrm{a}$ & $0,133 \mathrm{a}$ & $0,098 \mathrm{ab}$ & $0,310 \mathrm{a}$ \\
\hline C. V $\%)$ & 50,97 & 26,90 & 25,84 & 25,00
\end{tabular}

${ }^{1}$ Médias seguidas da mesma letra na vertical não diferem entre si ao nível de $5 \%$ de probabilidade, pelo teste de Tukey. $\mathrm{CV}=$ Coeficiente de variação.

Os tratamentos constituídos por regulador e estimulante vegetal aplicados via embebição nas sementes de jaca tipo dura, não favoreceram o acúmulo de massa seca da raiz, parte aérea e total de plantas. Os resultados encontrados divergem dos encontrados por Barros (2006) em que aplicação de $\mathrm{GA}_{3}$ via embebição em sementes de soja, algodão e arroz favoreceram essas características.

\section{CONCLUSÕES}

Os tratamentos de pré-embebição com os biorreguladores vegetais proporcionam melhorias no desempenho germinativo de sementes de jaca dura.

A pré-embebição das sementes de jaca dura em água destilada e Stimulate ${ }^{\circledR}$ a $10 \mathrm{~cm}^{3} \mathrm{dm}^{-3}$, por $2 \mathrm{~h}$, podem ser indicadas para a produção de mudas com maiores alturas.

\section{CONFLITOS DE INTERESSES}

Esse estudo foi aprovado pelo Comitê do Centro de Ciências Agrárias Ambientais e Biológicas da Universidade Federal do Recôncavo da Bahia que já realizou e realiza diversos trabalhos com os produtos dessa Empresa. 
LIMA, J.F. et al. Germinação de sementes pré-embebidas e crescimento...

\section{REFERÊNCIAS}

1. ARAGÃO, C. A. et al. Atividade aminolítica e qualidade fisiológica de sementes armazenadas de milho super doce tratadas com ácido giberélico. Revista Brasileira de Sementes, v. 25, n. 1, p. 43-48, 2003.

2. BARROS, T. F. Ação de giberelina líquida na germinação de sementes, vigor de plântulas e crescimento inicial de plantas. 2006. 53 f. Dissertação (Mestrado em Ciências Agrárias) - Centro de Ciências Agrárias Ambientais e Biológicas. Universidade Federal da Bahia, Cruz das Almas, 2006.

3. BEWLEY, J. D.; BLACK, M. Seeds: physiology of development and germination. 1. ed. New York: Plenum, 1986.367 p.

4. BORGHETTI, F.; FERREIRA, A. G. Interpretação de resultados de germinação. In: FERREIRA, A. G.; BORGHETTI, F. (Org.). Germinação : do básico ao aplicado. Porto Alegre: Artmed, 2004. p. 209-222.

5. DONADIO, L. C.; NACHTIGAL, J. C.; SACRAMENTO, C. K. do. Frutas exóticas. Jaboticabal: FUNEP. 1998. 279 p.

6. HÖFS, A. et al. Emergência e crescimento de plântulas de arroz em resposta á qualidade fisiológica de sementes. Revista Brasileira de Sementes, v. 26, n. 1, p. 92-97, 2004.

7. LIMA, J. F. PEIXOTO. C. P.; LEDO, C. A da S. Índices fisiológicos e crescimento inicial de mamoeiro (Carica papaya L.) em casa de vegetação. Ciência e Agrotecnologia, v. 31, n. 5, p. 1358-1363, 2007.

8. LORENZI, H. et al. Frutas brasileiras e exóticas cultivadas (de consumo in natura). São Paulo: Instituto Plantarum de Estudos da Flora Ltda, 2006. 672 p.

9. MANICA, I. Frutas nativas, silvestres e exóticas 2. Técnicas de produção e mercado: feijoa, figo-da-índia, fruta-pão, jaca, lichia, mangaba. Porto Alegre: Cinco Continentes, 2002. 541 p.

10. METIVIER, J. R. Dormência e germinação. In: FERRI, M. G. (Coord.) Fisiologia vegetal. São Paulo: Universidade de São Paulo, 1979. v. 2, p. 343-392.

11. MORAES, C. R. A.; MODOLO, V. A.; CASTRO, P. R. C. Fisiologia da germinação e dominância apical. In: CASTRO, P.R.C.; SENA, J.O.A.; KLUGE, R.A. (Ed.). Introdução à fisiologia do desenvolvimento vegetal, Maringá: UEM, 2002. p. 159-178.

12. PRADO NETO, M. et al. Germinação de sementes de jenipapeiro submetidas à pré-embebição em regulador e estimulante vegetal. Ciência e Agrotecnologia, v. 31, n. 3, p. 693-698, 2007.

13. SALISBURY, F. B.; ROSS, C. W. Plant physiology. 4. ed. California: Wadsworth, 1992. 682 p.

14. SOUSA, H. U. et al. Efeito do ácido giberélico sobre a germinação de porta-enxertos cítricos. Revista Brasileira de Fruticultura, v. 24, n. 2, p. 496-499, 2002.

15. STENZEL, N. M. C.; MURATA, I. NEVES, C. S. V. J. Superação de dormência em sementes de atemóia e fruta-deconde. Revista Brasileira de Fruticultura, v. 25, n. 2, p. 305-308, 2003.

16. STOLLER DO BRASIL. Stimulate ${ }^{\circledR}$ Mo em hortaliças. Cosmópolis: Stoller do Brasil-Divisão Arbore, 1998.1 p. (Informativo técnico, 1)

17. VIEIRA, E. L. Ação de bioestimulante na germinação de sementes, vigor de plântulas, crescimento radicular e produtividade de soja (Glycine max (L.) Merrill), feijoeiro (Phaseolus vulgaris L.) e arroz (Oriza sativa L.). 2001.122 p. Tese (Doutorado em Fitotecnia) - Escola Superior de Agricultura "Luiz de Queiroz", Universidade de São Paulo, Piracicaba, 2001.

18. VINHA S. G. da. Enxertia é solução para viabilidade da jaqueira. Informação e difusão, Itabuna: CEPEC - CEPLAC, n. 4, 1989. 2 p.

Recebido em 21/11/2008

Aceito em 11/08/2009 
